\title{
Components of Paraffin-Base and Naphthenic-Base Crude Oil and Their Effects on Interfacial Performance
}

\author{
Zhu Yin, Pingnan Yuan, Xiang Lian, Yancheng Zheng*, Heng Zheng \\ School of Chemistry and Environmental Engineering, Yangtze University, Jingzhou, China \\ Email: Yinzhu914@qq.com,770764538@qq.com, 346475260@qq.com, *zhengycg@163.com,295351608@qq.com
}

How to cite this paper: Yin, Z., Yuan, P.N., Lian, X., Zheng, Y.C. and Zheng, H. (2019) Components of Paraffin-Base and Naphthenic-Base Crude Oil and Their Effects on Interfacial Performance. Open Journal of Yangtze Gas and Oil, 4, 270-284. https://doi.org/10.4236/ojogas.2019.44022

Received: May 23, 2019

Accepted: October 7, 2019

Published: October 10, 2019

Copyright $\odot 2019$ by author(s) and Scientific Research Publishing Inc. This work is licensed under the Creative Commons Attribution International License (CC BY 4.0).

http://creativecommons.org/licenses/by/4.0/ CC) (i) Open Access

\begin{abstract}
The saturate, aromatics, resin and asphaltene components of paraffin-base (PB) and naphthenic-base (HB) crude oil are separated by chromatographic column. The acidic components of crude oil are extracted by compounded polar solvents and identified by methyl esterification of diazomethane. The acidic components before and after asphaltene removal are investigated by gas chromatography-mass spectrometer. The effect of four fractions in simulated oil on interfacial activity is discussed. The results show PB is rich in naphthalene series and tri-aromatic steroids, and $\mathrm{HB}$ has a high content of phenanthrene series, chrysene series and methylpyrene, besides higher content of naphthalene series. The long carbon chain acids in HB oil decrease significantly by asphaltenes removal, confirming the presence of heavy oil acids in asphaltene. A little amount of saturates and aromatics in simulated oil can reduce the interfacial tension (IFT). When the content of asphaltenes of simulated oil is increased, IFT is initially decreased and finally increased because of stability of asphaltenes. When resin is increased, IFT is initially increased and then decreased. Simulated oil containing the resin from naphthenic-base oil is more sensitive to alkali than that of paraffin-base resin, which can reduce the IFT between oil and water at a larger range.
\end{abstract}

\section{Keywords}

Component Separation, Carboxylic Acids, Group Composition, Paraffin-Base Oil, Naphthenic-Base Oil, Interfacial Activity

\section{Introduction}

The continuing exploitation of petroleum resources has been reducing residual oil reserves. It's difficult to extract crude oil in a conventional way after primary 
and secondary recoveries. Chemical flooding especially the surfactant flooding consequently becomes an important process for enhancing oil recovery. Efficiency of surfactant flooding for oil production depends not only on the properties of surfactants but also on the composition of crude oil [1]-[15]. In general, four fractions, such as saturate, aromatics, resin and asphaltene (SARA), have a considerable effect on crude oil exploitation respectively, especially for reducing $\mathrm{O} / \mathrm{W}$ interfacial tension (IFT). Non-hydrocarbon compounds, including resin and asphaltene being important active components in crude oil, can affect the interfacial properties between oil and aqueous surfactants solutions by its aromaticity and content [16] [17] [18] [19] [20]. In 2006, Hemmingsen et al. [21] found that acidic compounds from the crude oils could decrease the IFT between aqueous solution and crude oil, and increase the water-in-oil emulsion stability

Zhao et al. [22] confirmed that saturate and aromatics have a weak ability to affecting the properties of the oil phase and reaching ultra-low IFT between the oil phase and aqueous solution. IFT reduction of crude oil and surfactant aqueous solution is caused by adsorption of the polar fractions in crude oil at the interface to form a mixed film with betaine molecules. Further studies showed that the existence of strong alkali can improve the interfacial activity of fractions, and then reduce the IFT [23].

Acidic components rich in resin as a well-known strong interfacial active species play a major role in reducing O/W IFT [24] [25] [26] [27] [28]. Cao et al. [26] suggested that the mixed adsorption of positive synergistic effect between acidic components and linear betaine molecule on the interface of oil and solution might cause densification of interfacial film and reduction of O/W IFT. Whereas the mixed adsorption of acidic component and branched betaine molecules produces a negative synergistic effect to destroy the compactness of interfacial films, reduces the surfactant molecule number on the interface and ultimately increases the O/W IFT. Song et al. [29] and Samanta et al. [30] found that carboxylic acid from crude oil could be converted to surfactants in the presence of alkali and reduce IFT. Therefore, the composition of the crude oil is of great significance for improving oil recovery, especially polar component and group composition.

In this paper, group composition of SARA and acidic components in heavy oil and paraffin-based crude oil, separated by column chromatography and solvent extraction method respectively, and composition of aromatics from the two crude oil are analyzed by gas chromatography-quadrupole mass spectrometer (GC/MS). The effects of separation methods on the composition of petroleum acids are discussed. The difference of aromatics and acidic components from both crude oils and the effect of SARA content on IFT between surfactant solution and crude oil or kerosene are further studied. This study facilitates the understanding of the composition characteristics of heavy oil and paraffin-based crude oil, and their influence on the interfacial activity of surfactants used for oil displacement. 


\section{Materials and Methods}

\subsection{Materials}

The n-hexane, dichloromethane, chloroform, methanol, formic acid, isopropanol and ether are supplied by Tianjin Fuchen Chemical Reagent Factory with a purity of $99.7 \%$. N-methyl-N'-nitro-N-methyleneguanidine is supplied by Aladdin with a purity of $99.8 \%$. The kerosene is supplied by SINOPEC Jingmen Branch. PB crude oil, a paraffin-base crude oil with the acid value of $0.82 \mathrm{mg}$ $\mathrm{KOH} / \mathrm{g}$, is supplied by Qinghai Oilfield. $\mathrm{HB}$ crude oil, naphthenic-base oil and extra heavy oil with an acid value of $5.08 \mathrm{mg} \mathrm{KOH} / \mathrm{g}$ and viscosity of 33113 $\mathrm{mPa} \cdot \mathrm{s}$ at $50^{\circ} \mathrm{C}$, is supplied by Fengcheng Sinkiang Oilfield. C16AES and CDA are sulfonate surfactant and amide surfactant respectively, laboratory homemade, with the structure illustrated in Figure 1(a) and Figure 1(b).

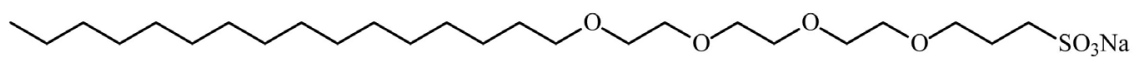

(a)

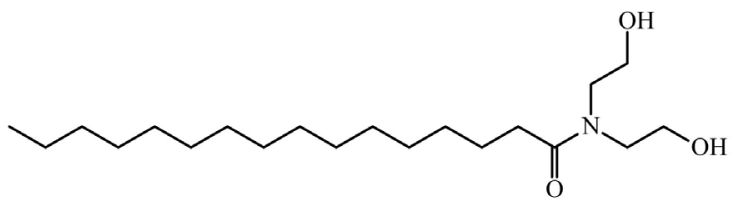

(b)

Figure 1. The structure of C16AES and CDA.

Silica gel with 100 - 200 mesh and $99.8 \%$ purity is supplied by Qingdao Puke Parting Materials Co. Ltd. which is calcined at $140^{\circ} \mathrm{C}-150^{\circ} \mathrm{C}$ for $8 \mathrm{~h}$ and for spare use. Neutral alumina with $100-200$ mesh and $99.8 \%$ purity is supplied by Sinopharm Chemical Reagent Co. Ltd., which is calcined at $400^{\circ} \mathrm{C}-450^{\circ} \mathrm{C}$ for 4 $\mathrm{h}$ and for spare use. Absorbent cotton is supplied by Xuzhou Weicai Hygienic Material Co. Ltd. which is refluxed by chloroform to no fluorescence.

The IFT is measured by TX-500C IFT Meter (U.S). The crude oil fractions are measured by Nicolet 6700 Fourier transform infrared spectroscopy (FTIR) and Agilent 7890/5975C (GC/MS). The HP-5MS column is used by temperature programming with a mobile phase of helium, the flow rate is $1.0 \mathrm{~mL} / \mathrm{min}$. Then the temperature of the column is raised to $300^{\circ} \mathrm{C}$ from $50^{\circ} \mathrm{C}$ at $10^{\circ} \mathrm{C} / \mathrm{min}$, staying for $10 \mathrm{~min}$ with the mass spectrometer interface temperature of $230^{\circ} \mathrm{C}$, bombarding energy of $70 \mathrm{eV}$, ion source temperature of $220^{\circ} \mathrm{C}$ and quadrupole temperature of $150^{\circ} \mathrm{C}$.

\subsection{Separation of Crude Oil Components}

The SARA is separated from two crude oils by referring to the industrial standard of China Petroleum SY/T5119-1995 with components of eluents changing. Firstly, 0.02 - 0.05 g crude oil and n-hexane are mixed in a conical flask, refluxed and kept undisrupted for overnight to obtain the precipitation of asphaltenes. The filtered solution is concentrated to $0.3-0.5 \mathrm{~mL}$. Secondly, $3 \mathrm{~g}$ silica gel and 2 
g neutral alumina are loaded in a column and retained a wad of absorbent cotton at the bottom. The column needed to be tapped lightly for filling the adsorbents evenly. Subsequently, $\mathrm{n}$-hexane is added for wetting the particles immediately followed by the concentrated filtered solution. The $n$-hexane, a mixture of $\mathrm{n}$-hexane and dichloromethane and a mixture of chloroform and methanol are successively added into the column to extract the saturates, aromatics and resins, respectively. Each of these fractions is concentrated by rotary evaporation and collected into a sample vial for next measurement.

The separated fractions are mixed with crude oils or kerosene at the range of $2 \%$ to $15 \%$ (wt $\%$ ) to form the simulated oil used for determining the effects of IFT between surfactant solutions and the oil phase.

\subsection{Separation of Acidic Components}

The acidic components are prepared by solvent extraction method [31]. Firstly, the isopropanol solution is saturated with $\mathrm{KOH}$, silica gel and chloroform are mixed and stirred for $5 \mathrm{~min}$ to obtain the modified silica gel. Secondly, the mixture is refluxed for $30 \mathrm{~min}$ by chloroform. Subsequently, a certain amount of crude oil, pre-dissolved in chloroform, is added into the extractor and refluxed for $6 \mathrm{~h}$. Upon refluxing by chloroform, the strong acidic fractions are extracted by a mixture of chloroform and formic acid (4:1, V: V) for $2 \mathrm{~h}$, then methyl is esterified by ether solution of diazomethane which is prepared from $\mathrm{N}$-methyl-N'-nitro-N-methyleneguanidine, concentrated for the next measurement.

\subsection{Measurement of IFT}

The IFT between water phase, $0.2 \%$ C16AES/CDA $(1: 2, \mathrm{~m} / \mathrm{m})$ surfactant solution prepared by $1.4 \% \mathrm{NaCl}+0.1 \% \mathrm{CaCl}_{2}$ salt solution, and internal phase, crude oil or the simulated oil, is measured at $50^{\circ} \mathrm{C}$ and a speed of $5000 \mathrm{r} / \mathrm{min}$. Each IFT test is repeated at least two times.

\section{Results and Discussion}

\subsection{Infrared Spectra Analysis}

Figure 2 and Figure 3 show infrared spectrograms of aromatics and acid fraction without methyl esterification in PB crude oil, respectively.

The skeleton vibration of rings, caused by stretching vibration of carbon atom in aromatic compound rings, has characteristic absorption peaks nearby 1600 $1585 \mathrm{~cm}^{-1}$ and $1500-1400 \mathrm{~cm}^{-1}$ respectively. Figure 2 shows that there are absorption peaks of aromatic compounds in PB crude oil at $1601 \mathrm{~cm}^{-1}$ and 1463 $\mathrm{cm}^{-1}$ respectively due to the difference of absorption peaks of the substituent on the ring. The heteroaromatics, monoaromatic and polycyclic compounds have similar skeleton vibrations.

In Figure 3, $1711 \mathrm{~cm}^{-1}$ is the absorption peak of the carboxylic acid dimer. The absorption peak, a wide spectrum band, at $2955-2854 \mathrm{~cm}^{-1}$ is the hydroxyl $\mathrm{O}-\mathrm{H}$ characteristics in a carboxylic acid. 


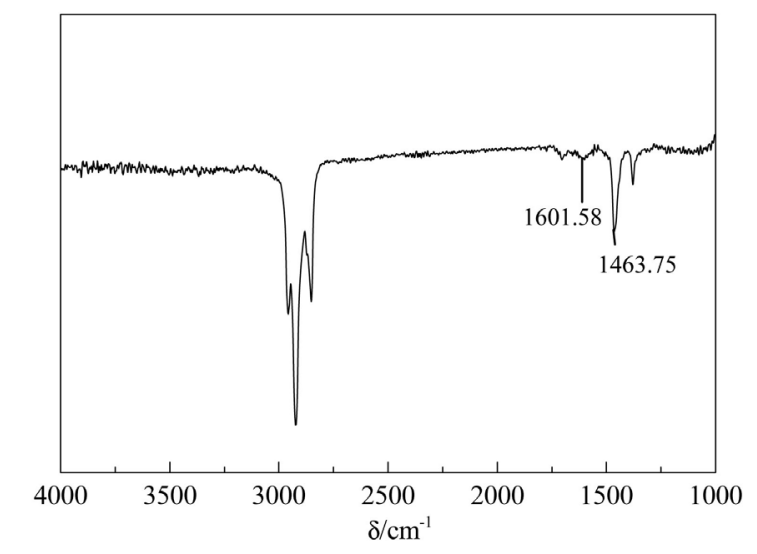

Figure 2. FTIR spectrum of oil aromatics from PB crude oil.

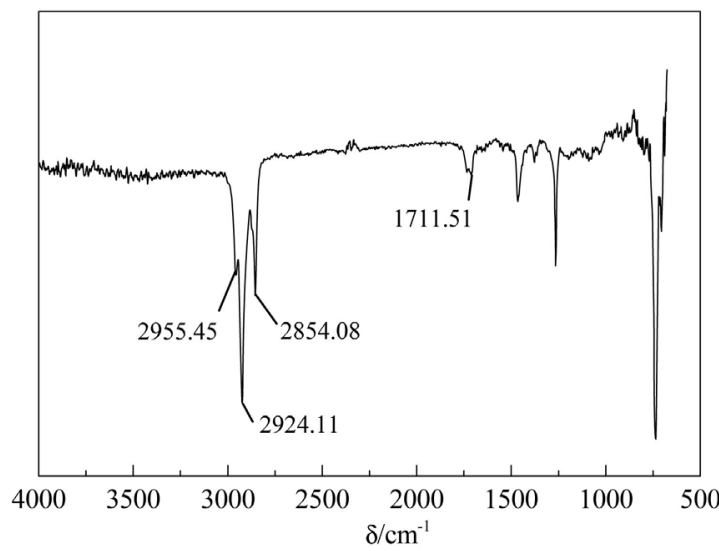

Figure 3. FTIR spectrum of organic acids from PB crude oil.

\subsection{Composition Difference of Aromatics from Paraffin-Base and Naphthenic-Base Crude Oils}

The composition of aromatics, extracted from paraffin-base crude oil PB and naphthenic-base crude oil HB, is authenticated and analyzed by GC/MS according to mass chromatogram [32] [33], the composition is listed in Table 1.

It can be seen from Table 1 that amount of naphthalene, phenanthrene and triaromatic steroid series in PB crude oil accounts for more than $83 \%$ of total aromatics, among which the triaromatic steroids with four rings with a content of $39 \%$ is the dominant component, followed by the phenanthrene series and naphthalene series with a content of $26 \%$ and $17 \%$, respectively. The content of aromatic hydrocarbon with two rings in $\mathrm{PB}$ crude oil is found to be $19.6 \%$, which is $7.5 \%$ higher than that of HB crude oil. The amount of naphthalene, phenanthrene, triaromatic steroid and chrysene series in naphthenic-base crude oil HB accounts for $84 \%$ of total aromatics, among which the phenanthrene series accounting for $46 \%$ is the dominant component, the contents of naphthalene series, chrysene series and triaromatic steroids are similar at the range from $11 \%$ to $15 \%$. The content of aromatics with three, four (except triaromatic steroid) and five rings in $\mathrm{HB}$ crude oil is found to be $33.6 \%$ higher than that in $\mathrm{PB}$ crude oil. 
Table 1. The composition of aromatics in PB and HB crude oil.

\begin{tabular}{|c|c|c|c|}
\hline Composition & Chemical structure & Content in PB crude oil (\%) & Content in HB crude oil (\%) \\
\hline Naphthalene series & & 17.71 & 11.07 \\
\hline Phenanthrene series & & 26.34 & 46.32 \\
\hline Chrysene series & & 4.33 & 11.06 \\
\hline Benzopyren + Methylpyrene & & 1.44 & 6.21 \\
\hline Thiophene series & & 4.77 & 2.82 \\
\hline Biphenyl series & & 1.87 & 0.97 \\
\hline Furanseries & & 1.65 & 1.06 \\
\hline Fluorene & & 2.37 & 2.92 \\
\hline Fluoranthene & & 0.13 & 0.96 \\
\hline Benzofluorene & & 0.20 & 0.94 \\
\hline Triaromatic steroid & & 39.19 & 15.65 \\
\hline
\end{tabular}

\subsection{Effect of Separation Method on the Composition of Organic Acid}

In this study, the acidic components are separated from asphaltene-free $\mathrm{HB}$ crude oil and HB crude oil, respectively. The GC/MS mass chromatograms of acidic components obtained by the two methods are shown in Figure 4 and Figure 5, respectively. 


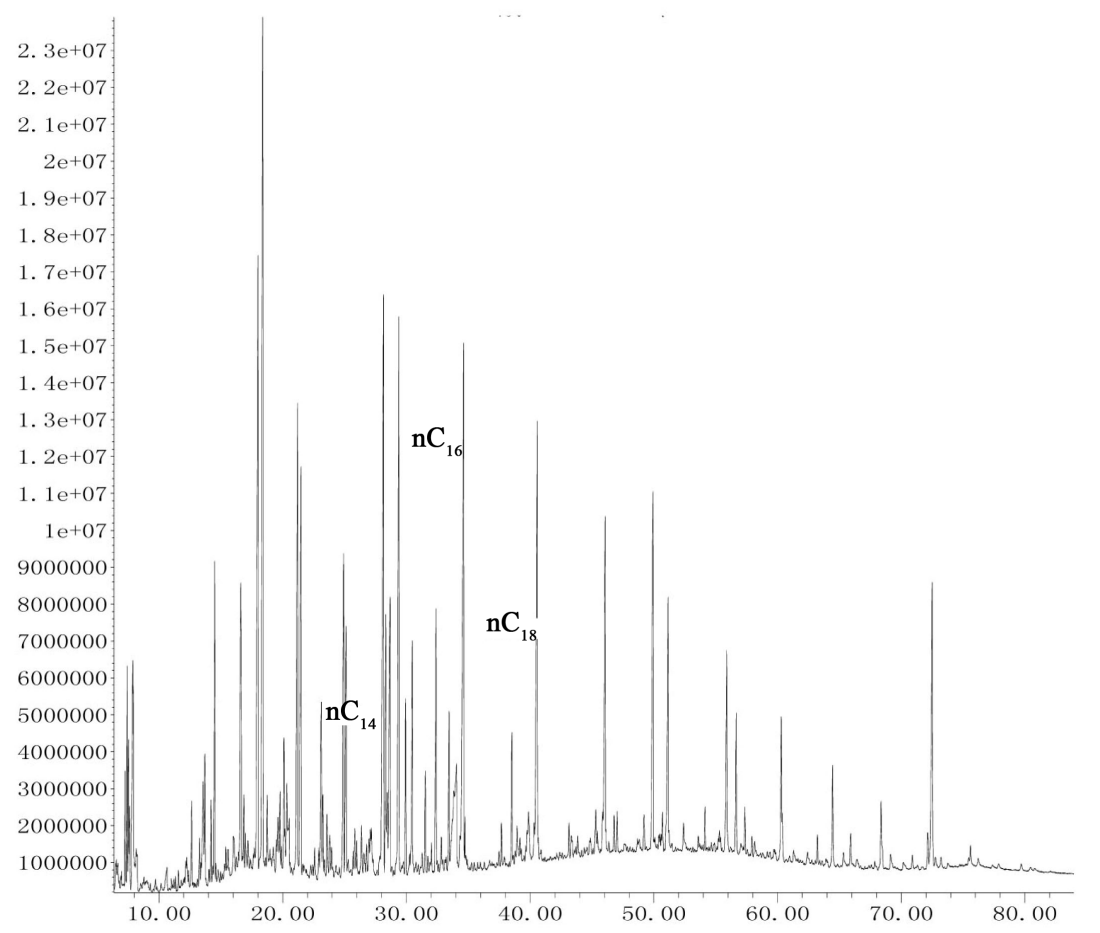

Figure 4. TIC ${ }^{\text {a }}$ Total Ion Chromatogram) of organic acid methyl ester in asphaltene-free $\mathrm{HB}$ crude oil. ${ }^{\star}$ The carbon number in figures represents aliphatic carbon number.

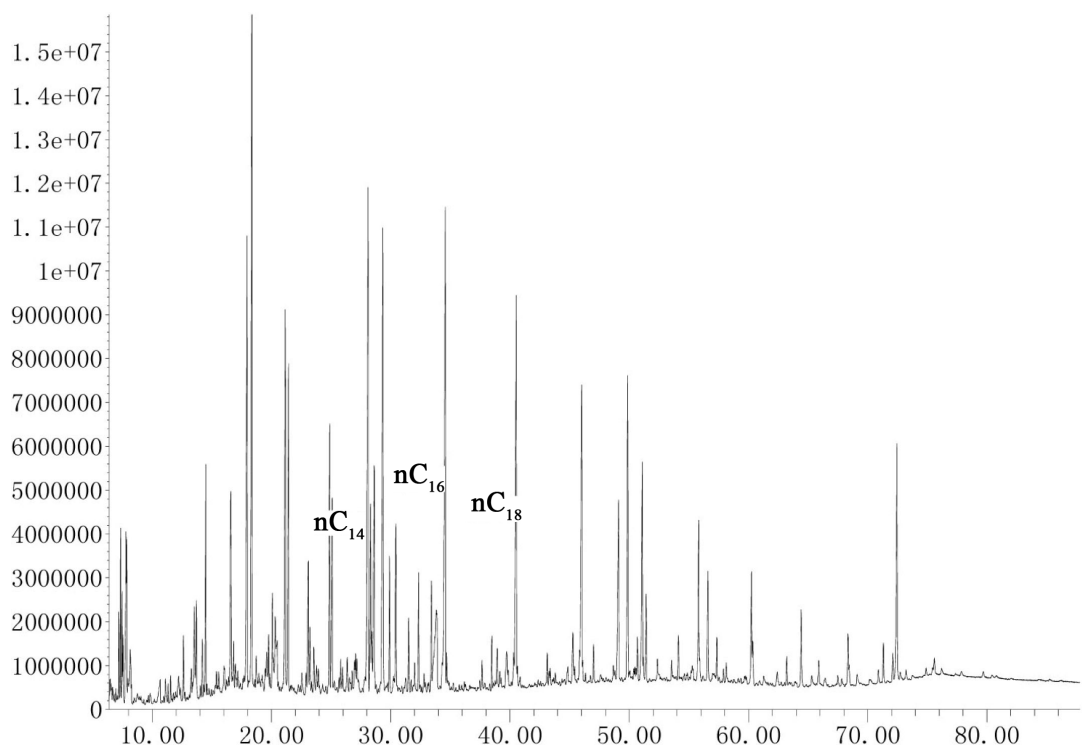

Figure 5. TIC of organic acid methyl ester in HB crude oil. ${ }^{\star}$ The carbon number in figures represents aliphatic carbon number.

For comparison, the morphologies of TIC of the methyl ester of the organic acid obtained by the two methods are basically identical. Table 2 shows the relative compositions of paraffinic acid separated from HB crude oil with and without asphaltene. Table 3 shows the compositions of carboxylic acid separated from $\mathrm{PB}$ and $\mathrm{HB}$ crude oils containing asphaltene. 
Table 2. The component of paraffinic acid in HB crude oil with and without asphaltene.

\begin{tabular}{cccccc}
\hline $\begin{array}{c}\text { Carbon number } \\
\text { of paraffinic acid }\end{array}$ & $\begin{array}{c}\text { HB crude oil } \\
\text { without } \\
\text { asphaltene (\%) }\end{array}$ & $\begin{array}{c}\text { HB crude } \\
\text { oil (\%) }\end{array}$ & $\begin{array}{c}\text { Carbon } \\
\text { number of } \\
\text { paraffinic acid }\end{array}$ & $\begin{array}{c}\text { HB crude oil } \\
\text { without } \\
\text { asphaltene (\%) }\end{array}$ & $\begin{array}{c}\text { HB crude } \\
\text { oil (\%) }\end{array}$ \\
\hline $\mathrm{C}_{9}$ & 1.843 & 2.258 & $\mathrm{C}_{18}$ & 21.479 & 20.893 \\
$\mathrm{C}_{10}$ & 2.173 & 2.858 & $\mathrm{C}_{19}$ & 0.149 & 0.155 \\
$\mathrm{C}_{11}$ & 0.944 & 1.096 & $\mathrm{C}_{20}$ & 0.453 & 0.621 \\
$\mathrm{C}_{12}$ & 12.996 & 14.21 & $\mathrm{C}_{21}$ & 0.129 & 0.040 \\
$\mathrm{C}_{13}$ & 0.634 & 0.757 & $\mathrm{C}_{22}$ & 0.251 & 0.381 \\
$\mathrm{C}_{14}$ & 3.653 & 4.36 & $\mathrm{C}_{23}$ & 0.136 & 0.190 \\
$\mathrm{C}_{15}$ & 1.609 & 1.794 & $\mathrm{C}_{24}$ & 0.274 & 0.502 \\
$\mathrm{C}_{16}$ & 52.294 & 48.806 & $\mathrm{C}_{25}$ & 0.099 & 0.105 \\
$\mathrm{C}_{17}$ & 0.763 & 0.77 & $\mathrm{C}_{26}$ & 0.122 & 0.203 \\
\hline
\end{tabular}

Table 3. The comparison of components between carboxylic acids in PB crude oil and HB crude oil.

\begin{tabular}{cccccc}
\hline $\begin{array}{c}\text { Carbon number of } \\
\text { carboxylic acid }\end{array}$ & $\begin{array}{c}\text { PB crude } \\
\text { oil (\%) }\end{array}$ & $\begin{array}{c}\text { HB crude } \\
\text { oil (\%) }\end{array}$ & $\begin{array}{c}\text { Carbon number } \\
\text { of carboxylic acid }\end{array}$ & $\begin{array}{c}\text { PB crude } \\
\text { oil (\%) }\end{array}$ & $\begin{array}{c}\text { HB crude } \\
\text { oil (\%) }\end{array}$ \\
\hline $\mathrm{C}_{9}$ & 0.5 & 2.258 & $\mathrm{C}_{20}$ & 0.591 & 0.621 \\
$\mathrm{C}_{10}$ & 0.696 & 2.858 & $\mathrm{C}_{21}$ & 0.221 & 0.04 \\
$\mathrm{C}_{11}$ & 0.461 & 1.096 & $\mathrm{C}_{22}$ & 0.389 & 0.381 \\
$\mathrm{C}_{12}$ & 9.299 & 14.21 & $\mathrm{C}_{23}$ & 0.196 & 0.19 \\
$\mathrm{C}_{13}$ & 0.431 & 0.757 & $\mathrm{C}_{24}$ & 0.425 & 0.502 \\
$\mathrm{C}_{14}$ & 3.861 & 4.36 & $\mathrm{C}_{25}$ & 0.191 & 0.105 \\
$\mathrm{C}_{15}$ & 2.000 & 1.794 & $\mathrm{C}_{26}$ & 0.275 & 0.203 \\
$\mathrm{C}_{16}$ & 54.416 & 48.806 & $\mathrm{C}_{27}$ & 0.112 & - \\
$\mathrm{C}_{17}$ & 0.924 & 0.77 & $\mathrm{C}_{28}$ & 0.146 & - \\
$\mathrm{C}_{18}$ & 24.455 & 20.893 & $\mathrm{C}_{29}$ & 0.07 & - \\
$\mathrm{C}_{19}$ & 0.257 & 0.155 & $\mathrm{C}_{30}$ & 0.083 & - \\
\hline
\end{tabular}

There is a certain effect of asphaltene removal on the content of the carboxylic acids in the crude oil. The naphthenic-base crude oil (HB) is taken as an example, the content of aliphatic acids (except $\mathrm{C}_{16}, \mathrm{C}_{18}$ and $\mathrm{C}_{21}$ aliphatic acid) in asphaltene-free crude oil is lower than that in crude oil containing asphaltene, the content of $\mathrm{C}_{19-26}$ aliphatic acid is decreased by $26.6 \%$ that is attributed to the removal of asphaltene, indicating that the aliphatic acids with high carbon number are removed by the precipitation of asphaltene, that is to say, heavy petroleum acids may also exist in asphaltene. This indicates that the organic acids should be separated directly from the crude oil in order to reveal the actual content of organic acids when analyzing the acidic components in crude oils, especially in the heavy oil.

The carbon number in paraffinic acids of paraffin-base crude oil (PB) and naphthenic-base crude oil (HB) ranges from 9 to 30 and 9 to 26, respectively. This indicates that the molecular weight of paraffinic acids in heavy oil with high viscosity is lower than that in the paraffin-base crude oil due to the degradation of n-alkanoic acids with high carbon number. In each of the alkanoic acid sepa- 
rated from the paraffin-base crude oil (PB) and naphthenic-base crude oil (HB), the content of $\mathrm{C}_{16}$ acid is the highest for both, which is $54.416 \%$ and $48.806 \%$, respectively. The contents of $\mathrm{C}_{18}$ acid and $\mathrm{C}_{12}$ acid decrease in an order, which are $24.455 \%$ and $9.299 \%$ respectively in the paraffin-base oil (PB), while $20.893 \%$ and $14.210 \%$ in the naphthenic oil (HB) respectively.

\subsection{Influence of Group Fractions of Two Crude Oils on Interfacial Activity}

\subsubsection{Minimum Carbon Number of Chains of $\mathrm{N}$-Alkanes $\left(\mathrm{N}_{\min }\right)$ of Mixed Surfactants}

The curve of equilibrium W/O IFT between different $\mathrm{n}$-alkanes and surfactant solution is shown in. Figure 6. It can be seen that the IFT first decreases then increases with the increase of the carbon number of $n$-alkanes. The minimum IFT reaches $0.0564 \mathrm{mN} / \mathrm{m}$ between $\mathrm{C}_{16}$ alkane and the aqueous phase which indicates that the $\mathrm{n}_{\min }$ value of the surfactant solution is 16 . When the carbon number of $\mathrm{n}$-alkanes is small the surfactant molecules are mainly dissolved in the water phase and difficulty for adsorbing onto the interface, which may be the reason of the high interface tension between $n$-alkanes and the aqueous phases. Based on the principle of dissolution in the similar material structure, the surfactant molecules move from the water phase to the $\mathrm{O} / \mathrm{W}$ interface on increasing of a carbon number of $n$-alkanes. For a specific surfactant solution, there is an $\mathrm{n}$-alkane with specific carbon chain length to make the distribution coefficient of the surfactant molecules in oil-water phases be 1 , the maximum amount of surfactant molecules is adsorbed to the interface, and the lowest IFT is obtained. As the chain length of $n$-alkane is increased, the surfactant molecules are believed to partition preferentially into the oil phase (n-alkane) rather than adsorbing on the interface, therefore the IFT increases [34] [35] [36].

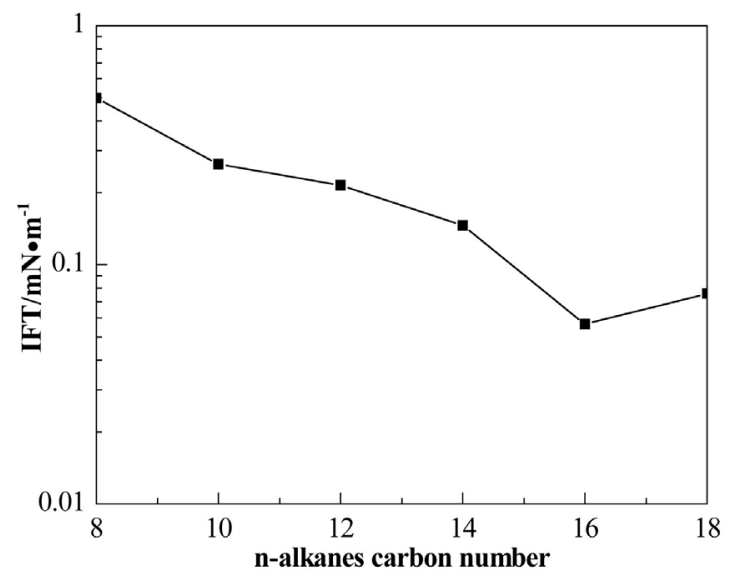

Figure 6. The effect of $n$-alkanes on oil/water IFT.

\subsubsection{Influence of Saturate Fraction on IFT}

The curves of IFTs between surfactant solution and two crude oils at different saturate contents are shown in Figure 7(a). It can be seen that the IFT decreases first and finally rises with the increasing of saturate content. IFT reaches the 
lowest level of $0.035 \mathrm{mN} / \mathrm{m}$ at a mass fraction of $10.89 \%$ for saturate in $\mathrm{PB}$ crude oil and $0.11 \mathrm{mN} / \mathrm{m}$ at a mass fraction of $11.06 \%$ for saturate in HB crude oil. The $\mathrm{O} / \mathrm{W}$ IFT between PB crude oil and the aqueous phase is low after the addition of a similar mass fraction of saturate.

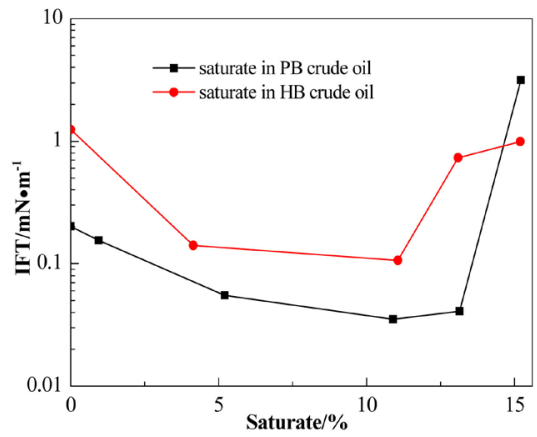

(a)

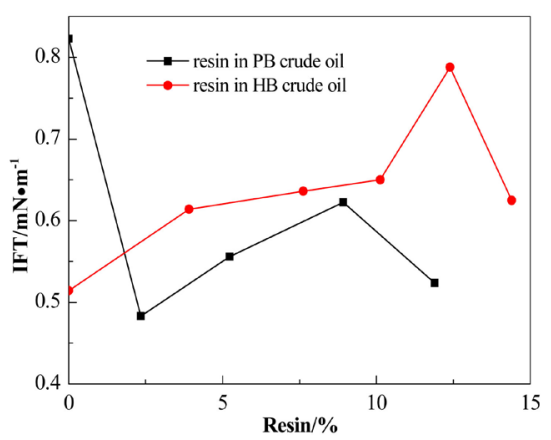

(c)

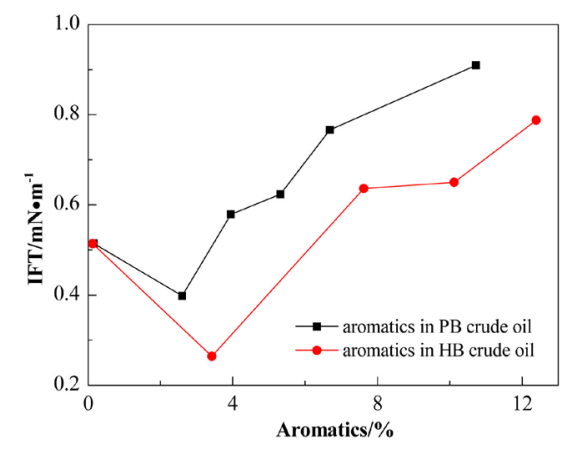

(b)

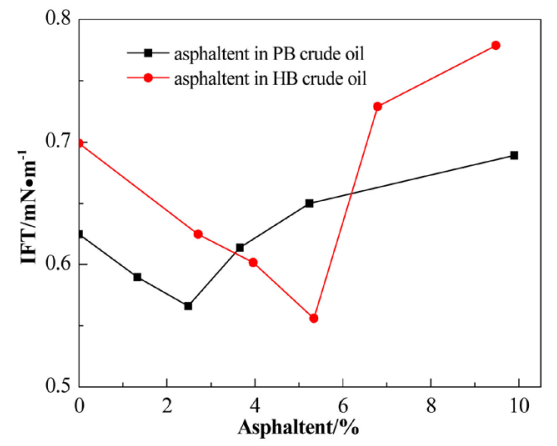

(d)

Figure 7. The effect of different SARA contents in crude oil and kerosene on oil/water IFT.

With the increasing of saturate content, IFT decreases first then rises, which mainly attributes to the increase of equivalent alkane carbon number (EACN) caused by the increasing of saturate with high carbon numbers in the oil phase and hydrophobicity [37]. When the EACN of crude oil is close to the $n_{\min }(16)$ of the surfactant solution, the surfactant tends to be enriched on the oil-water interface, and IFT decreases. For the increasing of saturate content, the number of surfactant molecules on the oil-water interface decreases, and IFT increases. This indicates that the addition of saturates with high carbon number leads to the change of the EACN of the oil phase, the partition of the surfactant in oil-water phases and interfacial activity [22] [24].

\subsubsection{Influence of Aromatics on IFT}

Kerosene with different aromatic contents is selected as the simulated oil for measuring equilibrium IFT between the oil phase and the surfactant solution. Figure 7(b) displays the experimental results.

It can be seen that a small amount of aromatics from both $\mathrm{PB}$ and $\mathrm{HB}$ can reduce the simulated oil-water IFT. The IFT between surfactant solution and si- 
mulated oil reaches the lowest with the value of $0.40 \mathrm{mN} / \mathrm{m}$ and $0.26 \mathrm{mN} / \mathrm{m}$ at the addition of $2.60 \% \mathrm{~PB}$ aromatics and $3.42 \% \mathrm{HB}$ aromatics into the simulated oil, respectively. The reduction of IFT may attribute to that aromatics including naphthalene series, benzopyrene, methylpyrene and fluorene etc. presented in simulated oil for altering the properties of oil phase at a certain content and hence reduce the IFT. Compared with PB crude oil being rich in bicyclic aromatics (such as naphthalene series) and triaromatic steroid, HB crude oil mainly contains aromatics with three and five rings. IFT between simulated oil containing $\mathrm{HB}$ aromatics and surfactant solution is lower, which indicates that aromatic hydrocarbons with fewer ring numbers facilitate the partition of surfactant molecules on the $\mathrm{O} / \mathrm{W}$ interface and effectively decrease IFT.

\subsubsection{Influence of Resin on IFT}

Figure 7 (c) shows the influence of resin separated from $\mathrm{PB}$ and $\mathrm{HB}$ crude oils on $\mathrm{O} / \mathrm{W}$ interfacial activity between kerosene and surfactant solution.

As shown in Figure 7(c), the kerosene-water IFT decreases after the addition of $\mathrm{PB}$ resin. With the increase of resin in kerosene, IFT increases then decreases. The IFT reaches the lowest level of $0.48 \mathrm{mN} / \mathrm{m}$ at $\mathrm{PB}$ resin content of $2.35 \%$. With the addition of $\mathrm{HB}$ resin, the kerosene-water interface tension increases first and then reduces. By comparison, HB resin has lower interfacial activity. This is because the active molecules with high molecule weights of resin separated from extra heavy oil preferentially adsorbe and enrich on the side of oil phase in the O/W interface [28].

\subsubsection{Influence of Asphaltene on IFT}

The kerosene with $0.93 \% \mathrm{~PB}$ aromatics and $0.44 \% \mathrm{HB}$ aromatics is served as the simulated oil. Asphaltenes extracted from PB and HB crude oils are added into the corresponding simulated oil. IFT between each simulated oil and surfactant solution was measured and shown in Figure $7(d)$.

As shown in Figure 7(d), IFT between each simulated oil and surfactant solution decreases first then increases with the addition of asphaltene. IFT of the system with $\mathrm{PB}$ asphaltene is the lowest value of $0.57 \mathrm{mN} / \mathrm{m}$ at asphaltene content of $2.48 \%$. While the IFT between simulated oil with $5.34 \% \mathrm{HB}$ asphaltene and surfactant solution reaches the lowest value of $0.55 \mathrm{mN} / \mathrm{m}$, which indicates that the system of simulated oil and surfactant solution reduces IFT at a lower addition of $\mathrm{PB}$ asphaltene. The content of the heavy acidic component of asphaltene will affect the distribution of surfactant molecules at $\mathrm{O} / \mathrm{W}$ interface and hence change the interfacial activities of surfactant solution.

\subsection{Influence of Alkali on IFT}

In consideration of large amounts of acidic components existed in the resin, carboxylic acids can react with the bases to form surfactants. IFT between simulated oils (kerosene $+11.89 \% \mathrm{~PB}$ resin, kerosene $+12.39 \% \mathrm{HB}$ resin) and a surfactant system containing $\mathrm{NaOH}$ is measured. Figure 8 shows the effects of the addition of alkali in simulated oil with $\mathrm{PB}$ or $\mathrm{HB}$ resin on $\mathrm{O} / \mathrm{W}$ IFT. 


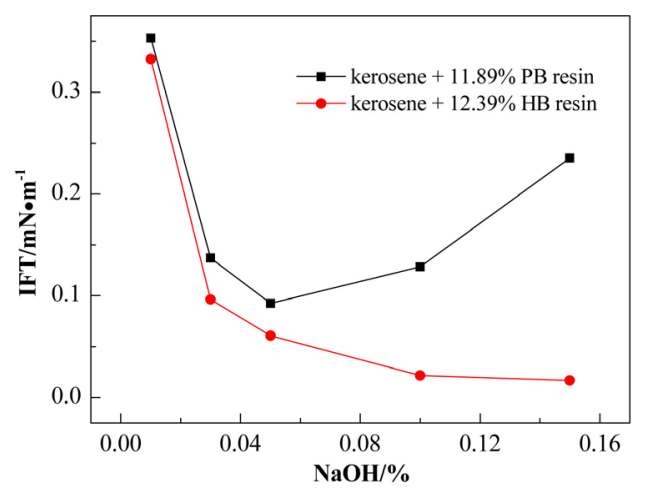

Figure 8. The effect of $\mathrm{NaOH}$ content on IFT of simulated oil with resin.

IFT reduces rapidly with the small addition of $\mathrm{NaOH}$. IFTs of the system with $\mathrm{HB}$ resin reduce to an order of magnitude of $10^{-2} \mathrm{mN} / \mathrm{m}$ at the addition of $0.05 \%$ alkali to simulated oil with the composition of kerosene $+12.39 \% \mathrm{HB}$ resin, which is lower than the system with PB resin. The IFTs of the system with $\mathrm{PB}$ resin and $\mathrm{HB}$ resin are $0.092 \mathrm{mN} / \mathrm{m}$ and $0.061 \mathrm{mN} / \mathrm{m}$ at the addition of $0.05 \%$ alkali, respectively. On further addition of alkali, IFT of the former system with resin in paraffin-base crude oil PB gradually increases, while the latter with resin in naphthenic-base crude oil HB decreases, which is attributed to the content and composition of organic acids from different oils, indicating that the acid components in naphthenic-base crude oil form activity substance and cause synergism effect of reducing IFT. Therefore, the resins from different crude oils have different sensitivities to alkali.

\section{Conclusions}

The crude oil SARA and acidic fractions of paraffin-base oil PB and naphthenic-base oil HB are separated by column chromatography and solvent extraction method, respectively. The structure of acidic components is confirmed by infrared spectroscopy and their acidic component is determined by esterification of diazomethane, followed by GC/MS analysis.

Tricyclic and above aromatic hydrocarbons in naphthenic-base oil HB are near twice of that in paraffin-base crude oil $\mathrm{PB}$. While the triaromatic steroids in $\mathrm{PB}$ and $\mathrm{HB}$ aromatic fraction are $39.15 \%$ and $15.65 \%$, respectively, indicating that the content of triaromatic steroid in $\mathrm{PB}$ oil is 2.5 times higher than that in HB oil.

The heavy acidic content with carbon numbers higher than 16 is reduced by the asphaltene removal of crude oil compared with the presence of asphaltene crude oil, which indicates that there is a certain amount of heavy petroleum acid included in the asphaltenes. The $\mathrm{C}_{9-30}$ paraffinic acids and $\mathrm{C}_{9-26}$ paraffinic acids are detected in paraffin-base crude oil (PB) and naphthene base oil (HB), respectively, indicating that the molecular weight of alkane acidic components in heavy oil is lower than that in crude oil with high paraffin.

Each of SARA in crude oil has an effect on the O/W interfacial activity. IFT value tends to decrease first, then increase with the increasing of SARA content 
in each crude oil or kerosene, except that the IFT value increases with the increasing of resin content of $\mathrm{HB}$ oil. The saturates can effectively change the EACN of the oil phase and the arrangement and distribution of surfactant molecules on $\mathrm{O} / \mathrm{W}$ interface at low content, thereby decreasing the IFT. HB aromatics can decrease IFT value more effectively than PB aromatics, owing to a large number of polycyclic aromatics in HB oil, especially phenanthrene, chrysene and benzopyren series in heavy oil. Compared to the HB resin, the PB resin is more effective in increasing the interfacial activity, while, the IFT between surfactant solution and $\mathrm{HB}$ resin is lower than that of $\mathrm{PB}$ resin in the presence of alkali, which can be attributed to that the acidic fractions in HB oil with much higher acid value than PB oil react with alkali to form carboxylate surfactants, and then low IFT value.

\section{Acknowledgements}

We gratefully acknowledge financial support by the National Natural Science Foundation of China (51474035).

\section{Conflicts of Interest}

The authors declare no conflicts of interest regarding the publication of this paper.

\section{References}

[1] Wang, Y.F., Xu, H.M., Yu, W.Z., et al. (2011) Surfactant Induced Reservoir Wettability Alteration: Recent Theoretical and Experimental Advances in Enhanced Oil Recovery. Petroleum Science, 8, 463-476. https://doi.org/10.1007/s12182-011-0164-7

[2] Ahmadi, M.A., Arabsahebi, Y., Shadizadeh, S.R. and Behbahani, S.S. (2014) Preliminary Evaluation of Mulberry Leaf-Derived Surfactant on IFT in an Oil-Aqueous System: EOR Application. Fuel, 117, 749-755. https://doi.org/10.1016/j.fuel.2013.08.081

[3] Guo, J.X., Shi, X., Yang, Z.G., et al. (2014) Synthesis of Temperature-Resistant and Salttolerant Surfactant SDB-7 and Its Performance. Petroleum Science, 11, 584-589. https://doi.org/10.1007/s12182-014-0375-9

[4] Liu, H.E., Zhang, X.K., Ding, C.Q. Chen, S. and Qi, X. (2014) Phase Behavior of Sodium Dodecyl Sulfate- $n$-Butanol-Kerosene-Water Microemulsion System. Chinese Journal of Chemical Engineering, 22, 699-705. https://doi.org/10.1016/S1004-9541(14)60095-1

[5] Lu, J., Weerasooriya, U.P. and Pope, G.A. (2014) Investigation of Gravity-Stable Surfactant Floods. Fuel, 124, 76-84. https://doi.org/10.1016/j.fuel.2014.01.082

[6] Romero-Zerón, L.B. and Kittisrisawai, S. (2015) Evaluation of a Surfactant Carrier for the Effective Propagation and Target Release of Surfactants within Porous Media during Enhanced Oil Recovery. Part I: Dynamic Adsorption Study. Fuel, 148, 238-245. https://doi.org/10.1016/j.fuel.2015.01.034

[7] Sheng, J.J. (2015) Status of Surfactant EOR Technology. Petroleum, 1, 97-105. https://doi.org/10.1016/j.petlm.2015.07.003

[8] Guo, K., Li, H.L. and Yu, Z.X. (2016) In Situ Heavy and Extra-Heavy Oil Recovery: 
A Review. Fuel, 185, 886-902. https://doi.org/10.1016/j.fuel.2016.08.047

[9] Raffa, P., Broekhuis, A.A. and Picchioni, F. (2016) Polymeric Surfactants for Enhanced Oil Recovery: A Review. Journal of Petroleum Science and Engineering, 145, 723-733. https://doi.org/10.1016/j.petrol.2016.07.007

[10] Bera, A., Mandal, A., Belhaj, H. and Kumar, T. (2017) Enhanced Oil Recovery by Nonionic Surfactants Considering Micellization, Surface, and Foaming Properties. Petroleum Science, 14, 362-371. https://doi.org/10.1007/s12182-017-0156-3

[11] Negin, C., Ali, S. and Xie, Q. (2017) Most Common Surfactants Employed in Chemical Enhanced Oil Recovery. Petroleum, 3, 197-211. https://doi.org/10.1016/j.petlm.2016.11.007

[12] Kang, W.L., Yin, X., Yang, H.B., et al. (2018) Demulsification Performance, Behavior and Mechanism of Different Demulsifiers on the Light Crude Oil Emulsions. Colloids and Surfaces A: Physicochemical and Engineering Aspects, 545, 197-204. https://doi.org/10.1016/j.colsurfa.2018.02.055

[13] Pal, S., Mushtaq, M., Banat, F. and Al Sumaiti, A.M. (2018) Review of Surfactant-Assisted Chemical Enhanced Oil Recovery for Carbonate Reservoirs: Challenges and Future Perspectives. Petroleum Science, 15, 77-102. https://doi.org/10.1007/s12182-017-0198-6

[14] Umar, A.A., Saaid, I.B.M., Sulaimon, A.A. and Mohd Pilus, R.B. (2018) A Review of Petroleum Emulsions and Recent Progress on Water-in-Crude Oil Emulsions Stabilized by Natural Surfactants and Solids. Journal of Petroleum Science and Engineering, 165, 673-690. https://doi.org/10.1016/j.petrol.2018.03.014

[15] Sun, L.D., Wu, X.L., Zhou, W.F., Li, X. and Han, P. (2018) Technologies of Enhancing Oil Recovery by Chemical Flooding in Daqing Oilfield, NE China. Petroleum Exploration and Development, 45, 673-684. https://doi.org/10.1016/S1876-3804(18)30071-5

[16] Peng, B., Li, M.Y., Zhao, S.Q., et al. (2003) Study of Oil/Water IFT of Vacuum Residual Fractions from Iranian Light Crude Oil. Chinese Journal of Chemical Engineering, 11, 681-685.

[17] Lashkarbolooki, M. and Ayatollahi, S. (2016) Effect of Asphaltene and Resin on IFT of Acidic Crude Oil/Sulfate Aqueous Solution: Experimental Study. Fluid Phase Equilibria, 414, 149-155. https://doi.org/10.1016/j.fluid.2016.01.032

[18] Lashkarbolooki, M. and Ayatollahi, S. (2017) Experimental and Modeling Investigation of Dynamic IFT of Asphaltenic-Acidic Crude Oil/Aqueous Phase Containing Different Ions. Chinese Journal of Chemical Engineering, 25, 1820-1830. https://doi.org/10.1016/j.cjche.2017.02.004

[19] Lashkarbolooki, M. and Ayatollahi, S. (2018) The Effects of pH, Acidity, Asphaltene and Resin Fraction on Crude Oil/Water IFT. Journal of Petroleum Science and Engineering, 162, 341-347. https://doi.org/10.1016/j.petrol.2017.12.061

[20] Sun, Z., Kang, X.D., Lu, X.G., Li, Q. and Jiang, W. (2018) Effects of Crude Oil Composition on the ASP Flooding: A Case from Saertu, Xingshugang and Lamadian Oilfield in Daqing. Colloids and Surfaces A: Physicochemical and Engineering Aspects, 555, 586-594. https://doi.org/10.1016/j.colsurfa.2018.07.021

[21] Hemmingsen, P.V., Kim, S., Pettersen, H.E., et al. (2006) Structural Characterization and Interfacial Behavior of Acidic Compounds Extracted from a North Sea Oil. Energy \& Fuels, 20, 1980-1987. https://doi.org/10.1021/ef0504321

[22] Zhao, R.H., Huang, H.Y., Dong, L.F., et al. (2012) Effect of Shengli Crude Oil Active Fractions on Oil-Water IFT of the System of Alkylbenzene Sulfonate Solution and the Active Fraction. Acta Petrolei Sinica (Petroleum Processing Section), 28, 827-833. (In Chinese) 
[23] Zhang, Q., Zhan, S.Y., Zhou, Z.H., et al. (2017) Effect of Crude Oil Fractions on the IFTs of Alkali-Betaine Mixed Solutions. Journal of Petroleum Science and Engineering, 159, 474-482. https://doi.org/10.1016/j.petrol.2017.09.056

[24] Zhao, R.H., Huang, H.Y., Wang, H.Y., et al. (2013) Effect of Organic Additives and Crude Oil Fractions on IFTs of Alkylbenzene Sulfonates. Journal of Dispersion Science and Technology, 34, 623-631. https://doi.org/10.1080/01932691.2012.685844

[25] Jiang, P., Li, N., Ge, J.J., et al. (2014) Efficiency of a Sulfobetaine-Type Surfactant on Lowering IFT at Crude Oil-Formation Water Interface. Colloids and Surfaces A: Physicochemical and Engineering Aspects, 443, 141-148.

https://doi.org/10.1016/j.colsurfa.2013.10.061

[26] Cao, J.H., Zhou, Z.H., Xu, Z.C., et al. (2016) Synergism/Antagonism between Crude Oil Fractions and Novel Betaine Solutions in Reducing IFT. Energy \& Fuels, 30, 924-932. https://doi.org/10.1021/acs.energyfuels.5b02566

[27] Zhang, J., Tian, D., Lin, M.Q. Yang, Z. and Dong, Z. (2016) Effect of Resins, Waxes and Asphaltenes on Water-Oil Interfacial Properties and Emulsion Stability. Colloids and Surfaces A: Physicochemical and Engineering Aspects, 507, 1-6. https://doi.org/10.1016/j.colsurfa.2016.07.081

[28] Andersen, S.I., Chandra, M.S., Chen, J., et al. (2017) Detection and Impact of Carboxylic Acids at the Crude Oil-Water Interface. Energy \& Fuels, 30, 4475-4485. https://doi.org/10.1021/acs.energyfuels.5b02930

[29] Song, X.W., Zhao, R.H., Cao, X.L., et al. (2013) Dynamic IFTs between Offshore Crude Oil and Enhanced Oil Recovery Surfactants. Journal of Dispersion Science and Technology, 34, 234-239. https://doi.org/10.1080/01932691.2012.658324

[30] Samanta, A., Ojha, K. and Mandal, A. (2011) Interactions between Acidic Crude Oil and Alkali and Their Effects on Enhanced Oil Recovery. Energy \& Fuels, 25, 1642-1649. https://doi.org/10.1021/ef101729f

[31] Wang, S. (1998) Polar Lipids in Green River Oil Shale as Facies Indicators. Carl Von Ossietzky University of Oldenburg,.

[32] Zhang, M. and Paul, P. (2010) Geochemical Characterization of Aromatic Hydrocarbons in Crude Oils from the Tarim, Qaidam and Turpan Basins, NW China. Petroleum Science, 7, 448-457. https://doi.org/10.1007/s12182-010-0097-6

[33] Huang, S.Y., Li, M.J., Zhang, K., et al. (2016) Distribution and Geochemical Significance of Phenylphenanthrenes and Their Isomers in Selected Oils and Rock Extracts from the Tarim Basin, NW China. Petroleum Science, 13, 183-191. https://doi.org/10.1007/s12182-016-0095-4

[34] Cayias, J.L., Schechter, R.S. and Wade, W.H. (1976) Modeling Crude Oils for Low IFT. Society of Petroleum Engineers Journal, 16, 351-357. https://doi.org/10.2118/5813-PA

[35] Cash, L., Cayias, J.L., Fournier, G., et al. (1977) The Application of Low IFT Scaling Rules to Binary Hydrocarbon Mixtures. Journal of Colloid and Interface Science, 59, 39-44. https://doi.org/10.1016/0021-9797(77)90336-8

[36] Wan, W., Zhao, J., Harwell, J.H. and Shiau, B.-J. (2016) Characterization of Crude Oil Equivalent Alkane Carbon Number (EACN) for Surfactant Flooding Design. Journal of Dispersion Science and Technology, 37, 280-287. https://doi.org/10.1080/01932691.2014.950739

[37] Chan, K.S. and Shah, D.O. (1980) The Molecular Mechanism for Achieving Ultra low IFT Minimum in a Petroleum Sulfonate/Oil/Brine System. Journal of Dispersion Science and Technology, 1, 55-95. https://doi.org/10.1080/01932698008962161 